Article

\title{
Evaluating the Diurnal Cycle of Upper Tropospheric Humidity in Two Different Climate Models Using Satellite Observations
}

\author{
Ajil Kottayil ${ }^{1, *}$, Viju O. John ${ }^{2,3}$, Stefan A. Buehler ${ }^{4}$ and Kesavapillai Mohanakumar ${ }^{1}$ \\ 1 Advanced Centre for Atmospheric Radar Research, Cochin University of Science and Technology, \\ Kerala 682022, India; kmkcusat@gmail.com \\ 2 EUMETSAT, Darmstadt 64295, Germany; vijuojohn@gmail.com \\ 3 Met Office Hadley Centre, Exeter EX1 3PB, UK \\ 4 Meteorological Institute, University of Hamburg, Hamburg 20146, Germany; \\ stefan.buehler@uni-hamburg.de \\ * Correspondence: ajilsat@gmail.com; Tel.: +91-8547-744-679
}

Academic Editors: Alfredo R. Huete and Prasad S. Thenkabail

Received: 24 December 2015; Accepted: 7 April 2016; Published: 13 April 2016

\begin{abstract}
The diurnal cycle of upper tropospheric humidity (UTH) is known to be influenced by such processes as convection and the formation of clouds which are parameterized in current global climate models. In this study, we evaluate the performance of two climate models, the Community Atmospheric Model version 5 (CAM-5) and the Global Atmosphere 3.0 (GA-3) model in simulating the diurnal cycle of UTH (represented by a combination of sinusoids of 12 and $24 \mathrm{~h}$ periods) by comparing with microwave and infrared (IR) measurements (where available). These comparisons were made over two convective land regions in South America and Africa, and over oceanic regions in the Atlantic, Indian and West Pacific for the month of January 2007. We analyzed how the diurnal cycles from IR and microwave instruments differ, and the reason for the differences. Our study suggests that the differences in the diurnal cycles of IR and microwave UTH result from sampling differences due to the presence of clouds. As noted by earlier studies, the models exhibit considerable discrepancies in diurnal amplitude and phase relative to observations, and these discrepancies have different magnitudes over land and ocean.
\end{abstract}

Keywords: upper tropospheric humidity; diurnal cycle; microwave; infrared; convection; climate models

\section{Introduction}

Climate models are the main tools for climate predictions so they need to take into account all relevant physical processes. However, there are processes, e.g., those associated with convection and the formation of clouds, that cannot be resolved at the model grid cell resolution and thus have to be parameterized, introducing potential uncertainties. Thus, to assess their reliability, models have to be validated against observations. Simulations of diurnal variations of different atmospheric variables are one of the important checks of the reliability of a model [1].

Solar forcing causes climate variables to have well defined patterns of variation that reoccur every $24 \mathrm{~h}$. The diurnal variation of upper tropospheric humidity (UTH) is closely tied to convection and clouds [2,3] so a comparison of modelled and observed diurnal variation of UTH can serve to check the fidelity of convective parameterization in the models. Conventional UTH measurements from radiosondes are sparse and their temporal sampling is generally limited to twice daily $(00.00$ and 12.00 UTC), which limits their use for studying diurnal variations of UTH [4]. Moreover, the reliability of UTH measurements from radiosondes remains questionable $[5,6]$. However, a global picture of the 
UTH distribution and its diurnal variations can ideally be obtained from satellite measurements from the infrared and microwave spectral ranges $[7,8]$.

The UTH mean state in climate models on monthly and seasonal time scales has already been validated against satellite observations in other studies. It was found that models exhibit regional moist and dry biases relative to the observations [9-13] and the biases can sometimes reach 100\%. Evaluations of humidity in the climate models participating in Coupled Model Inter-comparison Project phase-5 (CMIP5) by Tian et al. [14] and Jiang et al. [15] show that the model error in simulating humidity is largest in the upper troposphere. There are many studies that validate the simulation of the diurnal cycle of UTH in models using infrared satellite observations [16-18], and these are mostly data from geostationary platforms having full diurnal coverage. However, there are relatively few studies that evaluate model UTH diurnal cycles using microwave satellite observations. The upper tropospheric humidity dataset generated from microwave limb sounder measurements was used by Eriksson et al. [19] to evaluate UTH in climate models. A recent study by Chung et al. [20] used UTH from microwave measurements to evaluate diurnal cycle in reanalysis data. Using six months of observations from Superconducting Submillimeter-Wave Limb-Emission sounder (SMILES), Eriksson et al. [21] have studied the diurnal variation of upper tropospheric humidity.

In this study, we evaluate the simulation of UTH in the Community Atmospheric Model 5 (CAM-5) and the Met Office Hadley Centre GA-3 climate model using diurnal cycles constructed from microwave and infrared (IR) satellite measurements. The microwave measurements are less affected by the presence of clouds than infrared measurements. The validation of the diurnal cycle is performed over selected land and oceanic regions in the tropics for the month of January, 2007. The diurnal cycles of UTH from IR have been generated from METEOSAT satellite observations and those of microwave observations have been generated by combining data from four different polar orbiting satellites. Besides validating the climate models' diurnal cycles, this study investigates how the diurnal cycles from IR and microwave data differ from each other and the possible reasons for the differences. Our comparison between the diurnal cycles generated from microwave and IR measurements helps to understand how the sampling differences due to clouds affect the UTH diurnal cycle.

Section 2 provides the details of the satellite data and the climate models used in this study, Section 3 covers the methodology, and Section 4 presents the results and discussion. Section 5 presents the conclusions.

\section{Satellite Data and Models}

\subsection{Satellite Data}

The microwave data used in this study are from the Advanced Microwave Sounding Unit-B (AMSU-B) [22] onboard National Oceanic and Atmospheric Administration (NOAA) satellites 16 and 17 and the Microwave Humidity Sounder (MHS) [23] onboard NOAA-18 and MetOpA for the year 2007. The two instruments are very similar. They have a cross track scanning with horizontal resolution of $20 \times 16 \mathrm{~km}^{2}$ at nadir and $64 \times 27 \mathrm{~km}^{2}$ at the edge of the scan. Both have three tropospheric humidity sounding channels with a central frequency of $183.31 \mathrm{GHz}$. The passbands of these channels are centered at $183.31 \pm 1.00,183.31 \pm 3.00$, and $183.31 \pm 7.00 \mathrm{GHz}$ (only $183.31+7.00 \mathrm{GHz}$ for MHS). These channels sense the humidity variations in the upper, middle and lower troposphere, respectively. We will henceforth refer to these as channel 1, channel 2 and channel 3, respectively. In this study, we have used measurements from channels 1 and 3. Channel 3 is used for excluding the microwave UTH measurements contaminated by thick ice clouds; however, channel 2 can also be used.

The year 2007 has been chosen to maximize the availability of different satellite measurements in our analysis. NOAA-15 satellite measurements cannot be used in our study because of the large scan asymmetry affecting its channels [24]. A combination of these four satellites can only be used for the year 2007. Using the data prior to 2007 will exclude MetOpA from our analysis since the 
satellite launch was in October 2006. However, beyond 2007, NOAA-16 cannot be used because the measurements are not very reliable [24] due to high noise.

The NOAA and MetOpA satellites also have the 20 channel High Resolution Infrared Radiometer Sounder (HIRS) that provides simultaneous measurements of the atmospheric humidity and temperature distribution along with the microwave measurements. The scanning pattern and the spectral characteristics of these sensors can be found in http://www.ncdc.noaa.gov/oa/pod-guide/ ncdc/docs $/ \mathrm{klm} /$ index.htm. In this paper, we have used two HIRS channels which monitor UTH (channel 12; $\mathrm{Tb} 12(6.5 \mu \mathrm{m})$ ) and surface temperature (channel 8; $\mathrm{Tb} 8(11.1 \mu \mathrm{m})$ ). These measurements are used only for subsampling the microwave data and not for deducing the UTH diurnal cycle.

We have also used the Free Tropospheric Humidity (FTH) dataset constructed from METEOSAT satellite observations by the climate monitoring satellite application facility (CMSAF) of European Organisation for the Exploitation of Meteorological Satellites (EUMETSAT) (http://dx.doi.org/10. 5676/EUM_SAF_CM/FTH_METEOSAT/V001). These data are available from 1983 to 2009, with a horizontal resolution of $0.625^{\circ} \times 0.625^{\circ}$ and a temporal resolution of $3 \mathrm{~h}$. METEOSAT satellites are in geosynchronous orbits and the FTH is retrieved from the $6.3 \mu \mathrm{m}$ channel on-board these satellites [25].

\subsection{Climate Models}

The simulation of the UTH diurnal cycle has been evaluated for two climate models for the month of January, 2007. The first is the National Center for Atmospheric Research (NCAR) Community Atmospheric Model version 5 (CAM-5). The model output was available at a horizontal resolution of $1.9^{\circ} \times 2.5^{\circ}$ on 30 levels. Version 5 of CAM has several updated physics components with respect to cloud and convection and details can be found in Gettelman et al. [26,27] and Neale et al. [28].

The second climate model used in this study is the Global Atmosphere 3.0 (GA-3): a configuration of the Met Office Unified Model (MetUM) developed for use across climate research and weather prediction activities. A detailed description of the GA-3 configuration is given in Walters et al. [29]. The model outputs are on a $1.875^{\circ} \times 1.25^{\circ}$ longitude-latitude grid and on 85 levels .

Both model simulations use the same sea surface temperatures, sea ice fractions, $\mathrm{CO}_{2}$ concentrations and other external forcings as the Atmospheric Model Intercomparison Project (AMIP) framework of the CMIP5 [30]. Running the models with realistic forcings and boundary conditions significantly reduces systematic errors and makes the comparisons with observations as realistic as possible. For both models, outputs were stored every $3 \mathrm{~h}$, which was essential for constructing diurnal cycle as shown in MacKenzie et al. [17]. This temporal resolution is higher than the temporal resolution available in the AR5 archive.

\section{Methodology}

UTH from microwave measurements can be defined as the mean relative humidity (RH) with respect to water for the altitude range of $200-500 \mathrm{hPa}$. The diurnal cycles of UTH from observations and models are in each case approximated using a second order Fourier series given as,

$$
\mathrm{UTH}(t)=a_{0}+a_{1} \cos \frac{2 \pi\left(t-t_{1}\right)}{24}+a_{2} \cos \frac{2 \pi\left(t-t_{2}\right)}{12},
$$

where $t$ is the observational local time in hours, $a_{0}$ is the mean value of $\mathrm{UTH}, a_{1}$ is the amplitude of the $24 \mathrm{~h}$ oscillation, $a_{2}$ is the amplitude of the $12 \mathrm{~h}$ oscillation and $t_{1}$ and $t_{2}$ are the respective phases of the oscillations. The 24 and $12 \mathrm{~h}$ oscillations are commonly referred to as the diurnal and semidiurnal components. The diurnal amplitudes and phases are determined as described in Kottayil et al. [31]. The diurnal variation of UTH from models and observations was evaluated for the regions marked within black bordered boxes in Figure 1. The infrared based humidity data from METEOSAT were available only for the Atlantic (A-2) and African (A-3) regions, so the other regions use only microwave 
data. The red bordered region is a calibration region with minimal diurnal variation. Geographical locations of the regions marked in Figure 1 are summarized in Table 1.

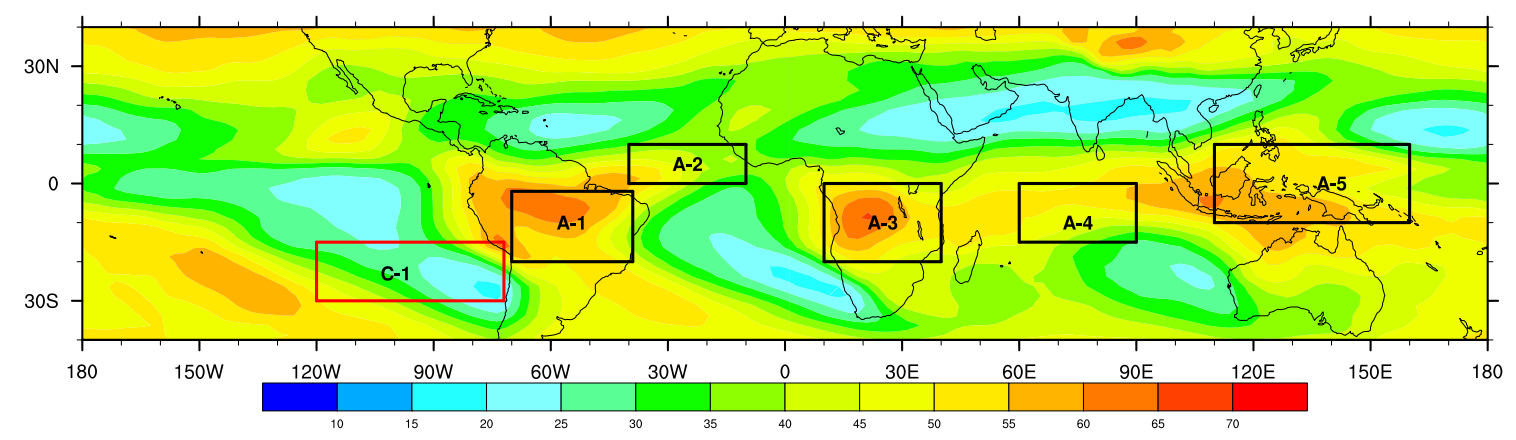

Figure 1. The mean UTH (\%RH) values for the month of January 2007 from the CAM-5 model (see text for details). The black rectangles are the regions chosen for looking at the diurnal cycle of UTH from models and observations. The red bordered rectangle is the region selected for calibrating the satellite measurements from microwave data.

Table 1. Geographical locations of the marked regions in Figure 1.

\begin{tabular}{cc}
\hline Region & Location \\
\hline South America (A-1) & $40^{\circ} \mathrm{W}-70^{\circ} \mathrm{W} ; 5^{\circ} \mathrm{S}-20^{\circ} \mathrm{S}$ \\
Atlantic (A-2) & $10^{\circ} \mathrm{W}-40^{\circ} \mathrm{W} ; 0^{\circ}-10^{\circ} \mathrm{N}$ \\
Africa (A-3) & $10^{\circ} \mathrm{E}-40^{\circ} \mathrm{E} ; 0^{\circ}-20^{\circ} \mathrm{S}$ \\
Indian Ocean (A-4) & $60^{\circ} \mathrm{E}-90^{\circ} \mathrm{E} ; 0^{\circ}-15^{\circ} \mathrm{S}$ \\
West Pacific (A-5) & $110^{\circ} \mathrm{E}-160^{\circ} \mathrm{E} ; 10^{\circ} \mathrm{N}-10^{\circ} \mathrm{S}$ \\
South East Pacific (C-1) & $70^{\circ} \mathrm{W}-120^{\circ} \mathrm{W} ; 15^{\circ} \mathrm{S}-30^{\circ} \mathrm{S}$ \\
\hline
\end{tabular}

\subsection{Diurnal Cycle from Microwave Measurements}

The channel 1 measurements from AMSU-B and MHS sensors, which monitor UTH variations, were filtered for any impact of cloud as described in Buehler et al. [32]. This cloud filter is based on the difference between channel 3 and channel 1 brightness temperatures and a threshold channel 1 value based on the viewing angle of the satellite, which is provided in Buehler et al. [32]. The cloud filtered channel 1 brightness temperatures were converted into UTH by the method described in Buehler and John [33] using the equation,

$$
\mathrm{UTH}=\exp \left(a \times T_{b}+b\right) .
$$

The coefficients $a$ and $b$ were determined using linear regression separately for each viewing angle of the satellite and are given in Buehler and John [33]. The mean value of $a$ in Equation (2) is -0.0735. It was shown in John et al. [34] that using coefficients for each viewing angle was sufficient to avoid the need for limb correction of the brightness temperatures. The daily UTH obtained from each of the satellites for the month of January 2007 was gridded onto a $2.5^{\circ} \times 2.5^{\circ}$ grid separately for the ascending and descending orbits. The gridded measurements from all the polar orbiting satellites were combined to create the diurnal cycle of UTH from microwave measurements for the month of January. For brevity, we will refer to the diurnal cycle deduced from microwave measurements as microwave diurnal cycle (MDC).

Prior to the construction of the diurnal cycles, inter-satellite biases in UTH were determined from one of the subsidence regions lying in the southeast Pacific (C-1) which is shown by the red bordered box in Figure 1. The UTH biases were determined by taking the MetOpA satellite as the reference. The inter-satellite bias of a particular satellite with respect to MetOpA is calculated as the difference between the monthly mean of the combined ascending and descending UTH values of MetOpA and 
that of the particular polar orbiting satellite. The absolute value of the inter-satellite biases determined for NOAA-16, 17,18 are $0.71 \% \mathrm{RH}, 0.35 \% \mathrm{RH}$ and $0.43 \% \mathrm{RH}$, respectively. The region surrounding the southeast Pacific was also used by Lindfors et al. [35] for determining the inter-satellite biases in HIRS measurements.

The subsidence region chosen for determining the inter-satellite bias is based on the assumption that the diurnal amplitudes of this region are smaller in comparison to other regions. To validate this assumption, we deduced the diurnal amplitudes of UTH from a subsidence region over the southeast Atlantic $\left(20^{\circ} \mathrm{W}-20^{\circ} \mathrm{E} ; 15^{\circ} \mathrm{S}-30^{\circ} \mathrm{S}\right)$ from IR data. The amplitudes $a_{1}$ and $a_{2}$ are $0.06 \% \mathrm{RH}$ and $0.11 \% \mathrm{RH}$ respectively. However, combining the ascending and descending orbits to deduce the inter-satellite biases can almost completely eliminate the $24 \mathrm{~h}$ amplitude $\left(a_{1}\right)$ of the diurnal cycle with a very small remnant diurnal amplitude $\left(a_{2}\right)$ [36].

To study the effect of clouds on IR data, an IR like diurnal cycle of UTH from microwave observations was constructed following the approach described in John et al. [37]. Following this approach, those microwave measurements are excluded whose corresponding collocated IR measurements are cloudy. The collocations were performed using the method described in Holl et al. [38]. The IR measurements collocated with microwave are treated as cloudy if the differences between $\mathrm{Tb} 12$ and $\mathrm{Tb} 8$ are less than $25 \mathrm{~K}$ [2]. The microwave observations sampled in this way were converted into UTH (Section 3.1) values which were then used to construct the diurnal cycle so as to mimic the clear sky only sampling of IR. This IR sampled diurnal cycle of microwave will be referred to as $\mathrm{MDC}_{\mathrm{IR}}$. The advantage of sub-sampling microwave data to mimic IR sampling is that it prevents errors that could arise from differences, for example, in vertical sampling of the instruments as described in John et al. [37].

\subsection{Diurnal Cycle from IR Measurements}

The FTH is retrieved from the METEOSAT $6.3 \mu \mathrm{m}$ (water vapor) channel measurements using the following relationship [39]:

$$
\ln \left(\frac{p_{0} R H}{\cos \theta}\right)=a \times T_{b}+b,
$$

where $p_{0}$ is a normalizing parameter equal to the ratio of the pressure of the $240 \mathrm{~K}$ isotherm to $300 \mathrm{hPa}$, $\mathrm{RH}$ is the average relative humidity with respect to water between $300-600 \mathrm{hPa}$ where the satellite measurements are sensitive, $\theta$ is the satellite viewing angle and $T_{b}$ is the $6.3 \mu \mathrm{m}$ brightness temperature. The coefficients $a$ and $b$ are the linear fitting coefficients. We have generated the diurnal cycle of FTH for January, 2007. The diurnal cycle from IR FTH data will be referred to as IRDC. In the paper, the terms FTH and UTH are used interchangeably where the former is represented as an equivalent of UTH from the IR measurements.

The cloud clearance in METEOSAT is based on the cloudy information from the International Satellite Cloud Climatology Project (ISCCP) data. The cloud clearance for day measurements of METEOSAT uses the cloud top pressure and the visible cloud reflectance albedo information from the ISCCP data while, for the night time cloud clearance, the cloud top pressure information alone is used [25].

\subsection{Diurnal Cycle from Models}

The microwave channel 1 brightness temperatures from models were simulated for the MetOpA satellite using the RTTOV V9.3 radiative transfer code, a component of the Cloud Feedback Model Inter-comparison Project (CFMIP) Observation Simulator Package (COSP) [40]. The brightness temperatures were simulated every $3 \mathrm{~h}$ for each model grid box with inputs of temperature and water vapor profiles and surface parameters from the model and an external input of ozone from the TOMS Ozone climatology provided for every $10^{\circ}$ latitude band separately for each month (http://toms.gsfc.nasa.gov/version8/v8tomsatbd.pdf). All the simulations were performed for the 
nadir viewing geometry. The brightness temperatures were converted into UTH using Equation (2) by applying the regression coefficients for nadir. The diurnal cycles of UTH from the models were then approximated using a second order Fourier series as in Equation (1).

\section{Results and Discussion}

Here, we present the evaluation of the diurnal cycle of UTH in climate models using satellite observations. The results are evaluated in terms of diurnal UTH range (DUR) from maximum to minimum and of the local times of maximum (LTMAX) and minimum (LTMIN) of UTH. We also analyze how the diurnal cycles generated from IR observations differ from those of microwave observations and suggest a plausible reason.

\subsection{Differences between IR and Microwave Diurnal Cycle}

We expect some systematic differences in the diurnal cycle from microwave and IR measurements because they are influenced differently by clouds. Notably, the stronger susceptibility of IR data to clouds relative to microwave data is expected to lead to a phase difference in the diurnal cycle. For the model data, the same effect can be taken into account to some extent by applying a cloud fraction filter.

Figure $2 \mathrm{a}, \mathrm{b}$ compare $\mathrm{MDC}$ and $\mathrm{MDC}_{\mathrm{IR}}$ for the region A-3. A lag of $1.65 \mathrm{~h}$ in the diurnal minimum of $\mathrm{MDC}_{\mathrm{IR}}$ with respect to $\mathrm{MDC}$ is seen, and an even larger lag of $3.5 \mathrm{~h}$ in the true IR diurnal cycle relative to microwave (Figure $2 b$ ). Does this lag stem exclusively from the sampling differences due to the presence of clouds? The microwave measurements used in constructing the diurnal cycle have a coarser temporal resolution compared to the IR measurements. The question may arise whether the coarser temporal resolution of microwave measurements is the reason for the shift in the diurnal minimum in the IR data relative to the microwave and this needs to be looked into. To check this, we constructed microwave like diurnal cycles of UTH from IR data. The diurnal cycles were constructed by sampling the IR data randomly, and matching the local observation times and the number of data points of microwave UTH measurements. Two hundred such diurnal cycles were constructed for the region A-3. The mean value and the one $\sigma$ uncertainty of the diurnal maximum and minimum from these diurnal cycles are determined to be $1.8 \pm 1.76$ local time (LT) and $18.38 \pm 1.89$ LT, respectively. The corresponding diurnal maximum and minimum for the IRDC over A-3 is 3.90 LT and 18.90 LT, respectively (red dotted lines in Figure $2 b$ ). Thus, the diurnal minimum value of the METEOSAT IR data lies within the uncertainty limits of the microwave sampled diurnal cycle. Since the phase shift between IR and microwave data is apparent in the diurnal minimum, this result points out that the temporal resolution of the microwave data is not a factor in determining the phase shift. This result also shows that the temporal resolution and the number of data points used in the microwave measurements can adequately represent the diurnal variations of UTH.

It has been shown in Sohn et al. [41] that the weighting functions of METEOSAT IR and the microwave UTH measurements lie in a similar altitude range and therefore this should not have caused the phase difference between the IR and the microwave diurnal cycles. They looked at the Special Sensor Microwave Water Vapor Profiler, SSM/T-2 where the upper tropospheric humidity channel is the same as of AMSU-B and MHS. Another factor which needed to be looked into for any impact on inferred diurnal cycle is the data spatial resolution used in the study since the microwave data has a spatial resolution of $2.5^{\circ} \times 2.5^{\circ}$ and IR data has a resolution of $0.625^{\circ} \times 0.625^{\circ}$. The IR UTH data were re-sampled onto a $2.5^{\circ} \times 2.5^{\circ}$ grid and the diurnal cycle created was compared with the IR data with the original available resolution of $0.625^{\circ} \times 0.625^{\circ}$. We find that the diurnal minimum of the resampled IR data leads the diurnal minimum of the IR data with $0.625^{\circ} \times 0.625^{\circ}$ resolution by $0.5 \mathrm{~h}$. This result indicates that a small part of the observed phase shift shown in the IR data relative to microwave originates from spatial resolution differences. In this respect, another reason could be the difference in the footprint sizes of the IR and the microwave measurements, but we have not investigated this in detail because the IR UTH data are available as gridded dataset. 

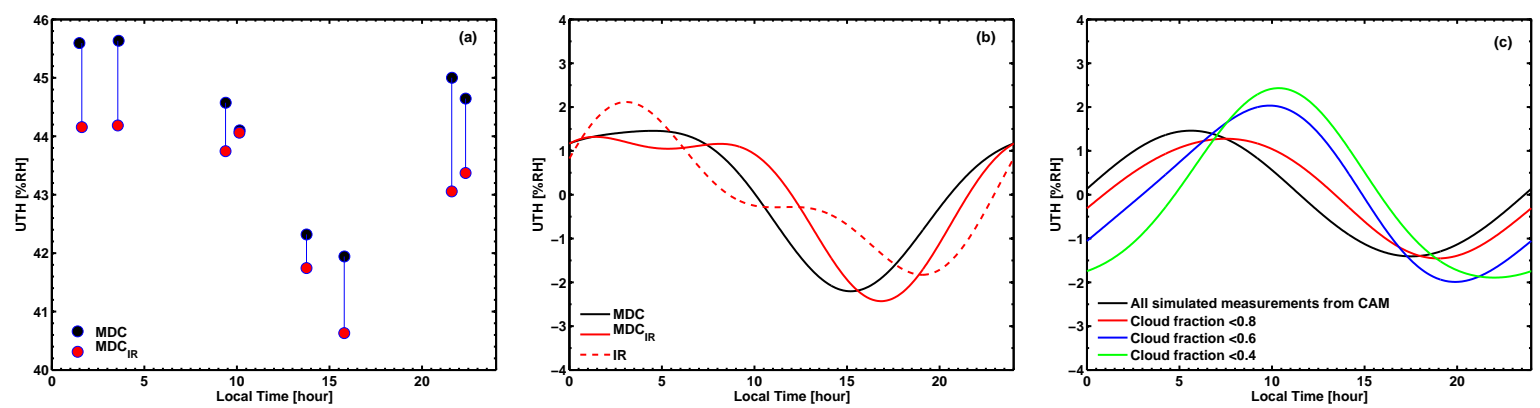

Figure 2. These results are for the African region (a): black and red circles show the diurnal cycle of UTH generated from microwave measurements in January 2007 using microwave sampling (MDC) and infrared samplings $\left(\mathrm{MDC}_{\mathrm{IR}}\right)$ respectively. See text for more details; $(\mathbf{b})$ : the corresponding diurnal cycle fit, the black line represents $M D C$ and the red line is for $M D C_{I R}$. The red dashed line represents the diurnal cycle from the real IR data (METEOSAT UTH data); (c): diurnal cycle of UTH from the CAM-5 model in January 2007 generated by filtering data for three different upper tropospheric cloud fraction (cf) thresholds. The black curve represents the diurnal cycle generated from all the simulated measurements.

It can be summed up from the above discussion that the sampling differences due to the presence of clouds are likely to be causing the phase shift in the IR data relative to microwave. The relatively higher lag shown by IRDC than the MDC $_{I R}$ could be due to the differences in the cloud clearance adopted in these datasets.

The phase shift in the diurnal minimum value in $M \mathrm{MC}_{\mathrm{IR}}$ relative to $\mathrm{MDC}$ is also seen for the other regions considered in this study. The time corresponding to the diurnal minimum of UTH has been inferred from the diurnal fits for both $\mathrm{MDC}_{\mathrm{IR}}$ and $\mathrm{MDC}$ and the difference between these times is defined as the phase shift. We have quantified the phase shifts over all the regions considered in the study and the results are tabulated in Table 2. Over South America (A-1), the lag is around $1.2 \mathrm{~h}$, over the Atlantic (A-2) it is $1.15 \mathrm{~h}$ and over the Indian Ocean (A-4) and the West Pacific (A-5), this is around $0.1 \mathrm{~h}$.

Table 2. Upper tropospheric humidity diurnal cycle lag due to cloudiness. Column 2: Measured lag in the diurnal phase in infrared sampled diurnal cycle $\left(\mathrm{MDC}_{\mathrm{IR}}\right)$ relative to microwave diurnal cycle (MDC) for different study regions. Column 3: Corresponding cloud fraction threshold required to show the same lag in CAM-5 model. The values within parentheses show the lag in the infrared diurnal cycle (IRDC) relative to MDC.

\begin{tabular}{ccc}
\hline Region & Measured lag (h) & Model cf Threshold \\
\hline A-1 & 1.2 & 0.72 \\
A-2 & $1.15(3.50)$ & 0.52 \\
A-3 & $1.65(3.00)$ & 0.78 \\
A-4 & 0.1 & 0.98 \\
A-5 & 0.1 & 0.76 \\
Tropics $\left(25^{\circ}\right.$ S-2 $\left.5^{\circ} \mathrm{N}\right)$ & 1.55 & 0.56 \\
\hline
\end{tabular}

We used all the simulated data from the models for the construction of diurnal cycle of UTH in order to compare with microwave measurements. This is because the microwave UTH measurements are affected only by thick clouds, so the cloud filtering method as described in Section 3.1 excludes only a small percentage (5\%) of the data [37]. However, differences in the diurnal cycle amplitude and phase constructed using microwave data filtered for thick clouds and without any filtering are very small. For example, over tropical land, the relative differences in amplitudes $a_{1}$ and $a_{2}$ calculated from Equation (1) is only 3\% without any significant differences in the phase. 
The model data comparison with IR UTH measurements is usually done by filtering the data based on modelled upper tropospheric cloud fraction $[10,11]$ to ensure a more or less similar comparison with IR. Therefore, the behavior of the diurnal cycle from the models filtered for different threshold values of cloud fraction is worth investigating. This will also give an insight into the optimum value of the cloud fraction threshold for comparing the diurnal cycle of UTH from models with IR observations.

In the CAM-5 model, the cloud fraction at each model layer is defined based on Neale et al. [28] as part of the cloud macrophysical package. It is a relative humidity based threshold value, which is consistent with the stratiform cloud condensate. We averaged the cloud fractions between 200 and $500 \mathrm{hPa}$ layer to get a representative value for the model's upper troposphere. We constructed the diurnal cycle of UTH from the CAM- 5 model by filtering the data for three different values of average upper tropospheric cloud fraction. These threshold values are $0.4,0.6$ and 0.8 , and the model data exceeding these thresholds are excluded from the construction of the diurnal cycle. These results are shown in Figure 2c. The diurnal cycle generated without any filtering is also shown. As the figure shows, the diurnal cycle in UTH filtered for cloud fraction 0.8 shows a shift in the diurnal phase of UTH with respect to the unfiltered diurnal cycle by almost the same magnitude as shown by MDC IR. On the other hand, the diurnal cycle generated with a cloud fraction of 0.4 , a typical threshold value used in model and IR UTH comparisons, shows a lag of more than $4 \mathrm{~h}$ in the LTMAX and LTMIN with respect to the diurnal cycle created without any filtering.

We have also calculated the cloud fraction thresholds over the other study regions so that they can be used as indicative values for model and IR data comparisons. The results are presented in Table 2. These modeled cloud fraction values vary from region to region, ranging from 0.52 in A-2 to 0.98 in A-4. This suggests that choosing a right threshold for the upper tropospheric cloud fraction is important to ensure meaningful comparisons. A caveat here is that these values can vary from model to model.

\subsection{Diurnal Cycle in Models and Observations}

To compare with microwave observations, the diurnal cycle from model data was generated without any cloud fraction threshold filtering. The diurnal cycles of UTH from models and observations over the land regions in South America (A-1) and Africa (A-3) in January 2007 are shown in Figure 3. These are the convective regions occurring over land during the month of January.
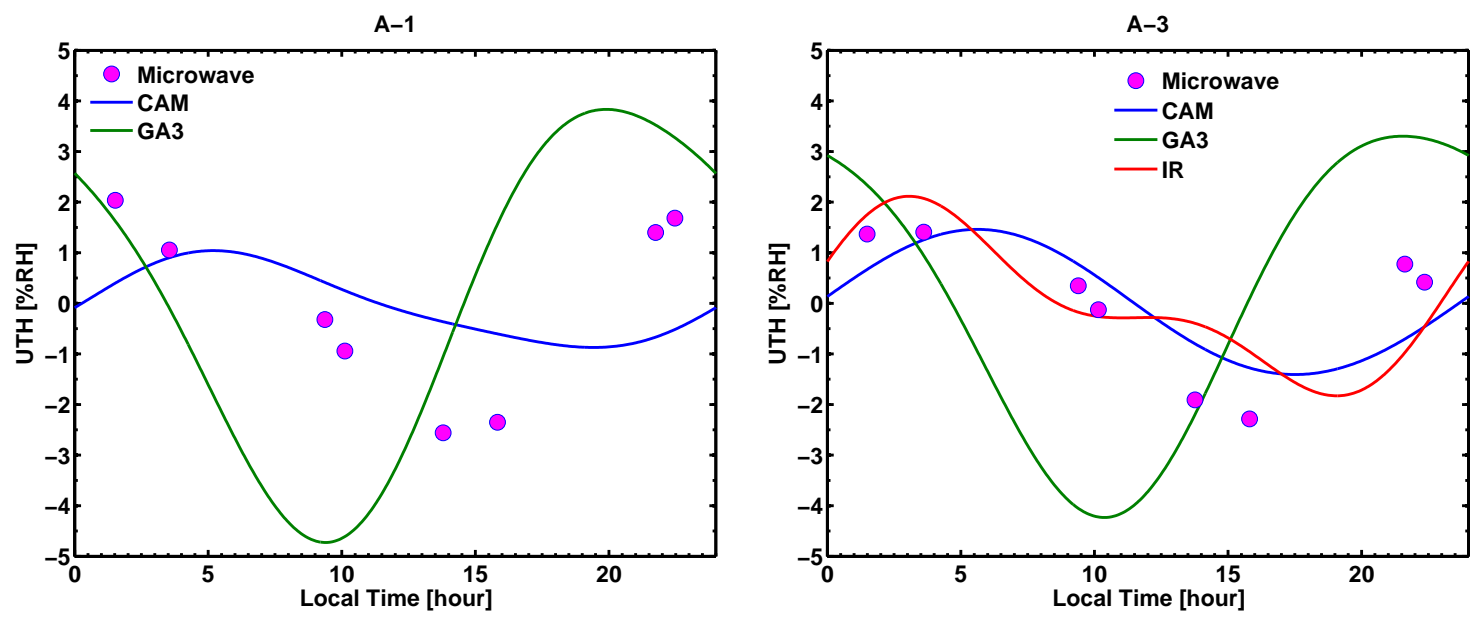

Figure 3. The diurnal cycle of UTH from the models and observations for land regions over South America (A-1) and Africa (A-3) for January 2007 (mean values are subtracted from UTH). The IR refers to infrared diurnal cycle. 
Over South America (A-1), the DUR from microwave observation is $4.5 \% \mathrm{RH}$ while the models show significant differences. Compared to the observation, the GA-3 model overestimates the DUR with 7.5\% RH whilst the CAM-5 model underestimates the DUR with $2 \%$ RH. The LTMAX and LTMIN in the MDC are approximately 2 LT and 14 LT, respectively. The models exhibit different local times for LTMAX and LTMIN. The LTMAX in the CAM-5 model lags by $3.00 \mathrm{~h}$ and the LTMIN lags by $5.00 \mathrm{~h}$ with respect to the MDC with respective local times of nearly 5 LT and 19 LT. On the other hand, the LTMAX of the GA-3 model leads the MDC by $6.00 \mathrm{~h}$ and the LTMIN of the GA-3 leads by $5.00 \mathrm{~h}$.

Over Africa (A-3), the DUR of microwave observation is 3.5\% RH. The LTMAX in microwave occurs at the same local times as in region A-1 but the LTMIN occurs at around 16 LT. The magnitude of DUR in models is almost the same as region A-1. The LTMAX and LTMIN in the GA-3 model occurs at 22 LT and 10 LT while in the CAM-5 model, the LTMAX and LTMIN are at 5 and 18 LT. The IRDC shows a lag of approximately $3.5 \mathrm{~h}$ in the LTMIN relative to the microwave observations which could be due to the sampling differences as described in Section 4.1.

Figure 4 shows the diurnal cycle of UTH from the models and observations for the selected convective oceanic regions. The MDC DUR is approximately $2 \% \mathrm{RH}$ over all the oceanic regions. The MDC LTMAX is nearly 2 LT except over the region A-5 where it is nearly at 22 LT. The MDC LTMIN is at the same local time (14 LT) over all the oceanic regions. The diurnal phase and amplitude of IR and microwave data are comparable for the Atlantic region.
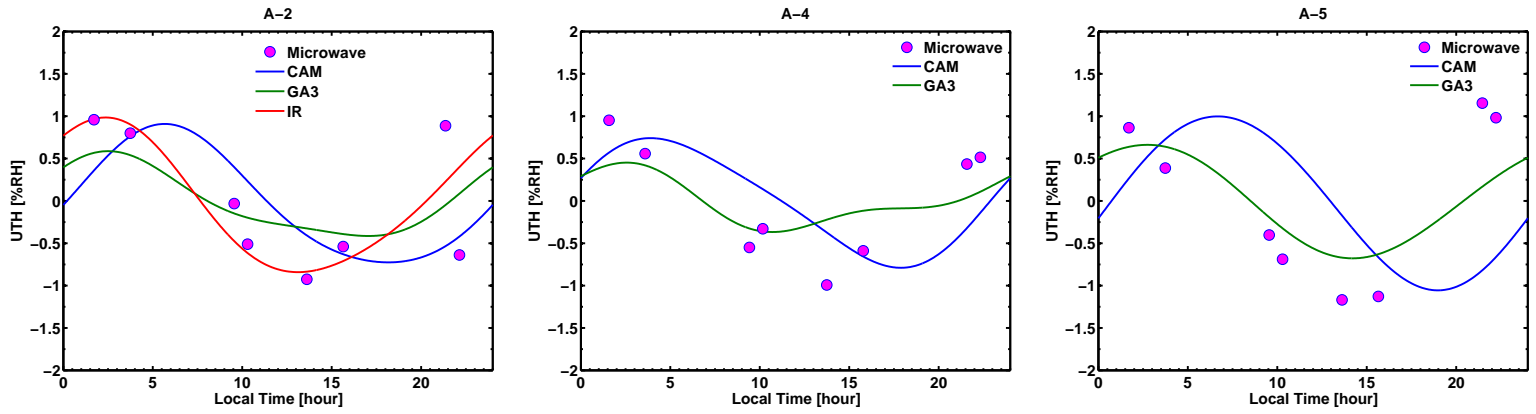

Figure 4. Same as Figure 3 but for the Atlantic (A-2), Indian Ocean (A-4) and the West Pacific (A-5).

The CAM- 5 model shows a DUR of $1.5 \%$ RH in the Atlantic (A-2) and the Indian ocean (A-4) and $2 \%$ RH over the West Pacific (A-5). The CAM-5 model UTH lags the microwave observations. The LTMAX in the CAM- 5 model in A-2, A-4 and A-5 occurs at 5 LT, 4 LT and 7 LT, whereas the corresponding LTMIN occurs around 18 LT in all these regions. It is to be noted that the diurnal cycle of UTH shown for CAM-5 model is in agreement with the simulation from CAM-3 model as shown by [19].

The GA-3 model shows $0.8 \%$ RH for DUR in A-2 and A-4 and a slightly higher value of $1.2 \%$ RH in A-5. The LTMAX in GA-3 occurs nearly at 2 LT for all the regions which is in agreement with the MDC in regions A-2 and A-4. The LTMIN in GA-3 occurs at 17 LT, 10 LT and 11 LT in A-2, A-4 and A-5 respectively. The results from models and observation are summarized in Table 3.

The diurnal cycle of UTH in observations shown for convective land and oceanic regions are in good agreement in terms of the diurnal maximum and minimum values, with much stronger diurnal amplitudes over land regions in comparison to oceanic regions [19,42]. Chung et al. [42] used METEOSAT- 8 measurements over A-2 and A-3 to analyze the diurnal cycles of upper and mid-tropospheric humidity in conjunction with the diurnal cycles of clouds and precipitation.

Figures 3 and 4 show that the DUR, LTMAX and LTMIN in models differ from that of the microwave observations. According to the observational studies so far, the diurnal cycle of UTH is regulated by the diurnal cycle of cirrus anvil cloud which follows after deep convective events [2]. It is shown in Soden [3] that the formation and the dissipation of cirrus anvil cloud regulates the moistening of the upper troposphere. Hence, in the models, the diurnal cycle of deep convective 
clouds along with UTH should be analyzed to gain a first hand understanding of the differences from the observations (e.g., Zhang et al. [18]).

Table 3. The diurnal range (DUR), diurnal maximum and minimum (LTMAX \& LTMIN) from observations and models. The unit of DUR is in \% RH and LTMAX and LTMIN is in local time of observation.

\begin{tabular}{|c|c|c|c|c|c|c|c|c|c|}
\hline \multirow{2}{*}{ Region } & \multicolumn{3}{|c|}{ Observation } & \multicolumn{3}{|c|}{ GA-3 } & \multicolumn{3}{|c|}{ CAM-5 } \\
\hline & DUR & LTMAX & LTMIN & DUR & LTMAX & LTMIN & DUR & LTMAX & LTMIN \\
\hline A-1 & 4.5 & 2 & 14 & 7.5 & 20 & 9 & 2 & 5 & 19 \\
\hline A-2 & 2 & 2 & 14 & 0.8 & 2 & 17 & 1.5 & 5 & 18 \\
\hline A-3 & 3.5 & 2 & 16 & 7 & 22 & 10 & 2 & 5 & 18 \\
\hline A-4 & 2 & 2 & 14 & 0.8 & 2 & 10 & 1.5 & 4 & 18 \\
\hline A-5 & 2 & 22 & 14 & 1.2 & 2 & 11 & 2 & 7 & 18 \\
\hline
\end{tabular}

We analyzed as to how the diurnal cycles of deep convection and UTH are related in the observations and climate models. For the representation of the diurnal cycle of deep convection in the observation, we use the ISCCP data available at $3 \mathrm{~h}$ temporal resolution for January [43]. The percentage of occurrence of deep convective clouds from ISCCP has been used to construct the diurnal cycle of convection. This data is available from http://mwac.its.monash.edu/mwac/pub/ listPubCollections.jspx. For the models, we use the diurnal cycle of Ice Water Path (IWP) to represent the diurnal cycle of convection. The CAM- 5 model includes only the ice cloud data for the calculation of IWP whereas the GA-3 model run takes both ice cloud and precipitating ice/snow for the computation of IWP.Therefore, the model biases in IWP could be larger in CAM-5 as compared to GA-3.

The diurnal cycle of deep convection and UTH in models and observations over tropical $\left(25^{\circ} \mathrm{S}-25^{\circ} \mathrm{N}\right)$ land region is shown in Figure 5. The diurnal peak of deep convection in observations occurs nearly at $18 \mathrm{LT}$ and UTH peak time lags the deep convection almost by $8 \mathrm{~h}$. This result is in agreement with Chung et al. [42] and Eriksson et al. [19]. The late afternoon peak time for the upper tropospheric IWP from SMILES observations has been shown in Millan et al. [44]. The diurnal cycle of IWP retrieved from SMILES has also been used by Jiang et al. [45] to evaluate the climate model simulations. The GA-3 model shows nearly the same peak time for IWP and UTH which is around $19 \mathrm{LT}$. This contradicts the observed lag of $8.00 \mathrm{~h}$ in the UTH maximum relative to the deep convection maximum in the observations. However, in CAM-5, the lag in UTH relative to IWP is close to $9 \mathrm{~h}$ which is nearly in agreement with the observations though the peak time of both UTH and deep convection differs from the observations by around $3 \mathrm{~h}$.

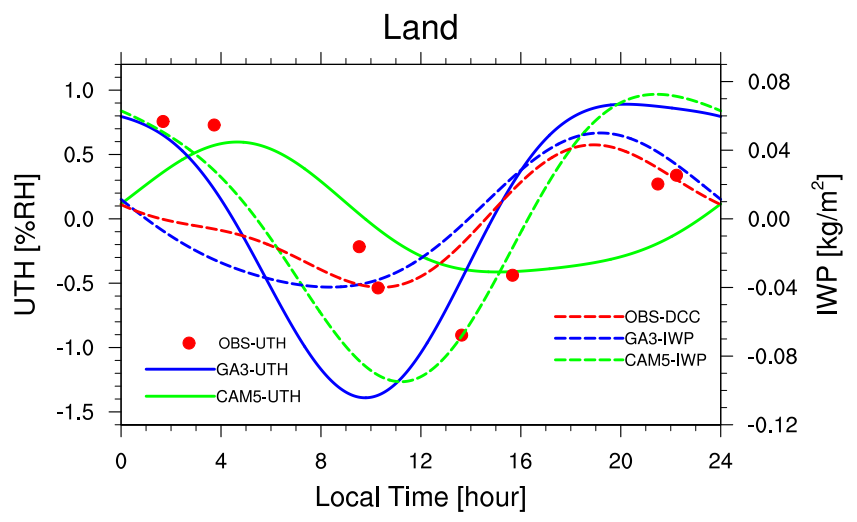

Figure 5. Diurnal cycle of UTH and deep convection in observation and models for January 2007 for tropical land regions. The OBS in the legend stands for observation, DCC for deep convection and IWP stands for Ice Water Path. 
These results show that, most likely, the parameterization of cloud and convective processes in the models may not be good enough to resolve the evolution of humidity in the model grid cell following the convective events. It has also been shown that large-scale advection [46] can play a role in the distribution of UTH, but there are no studies as to how it modulates the diurnal cycle of UTH. In addition to understanding the role of convection and large scale circulation in regulating the upper tropospheric humidity, other factors affecting UTH for example aerosols, should also be investigated [47]. The vertical resolution of an instrument is also an important factor for accurate monitoring of diurnal variation of tropospheric humidity and clouds [48,49].

\section{Conclusions}

We have evaluated the diurnal cycle of UTH in two climate models, CAM-5 and GA-3, using satellite microwave and IR observations. The diurnal cycle in the models has been evaluated for some of the convective tropical regions over land and ocean for the month of January 2007. The models show considerable differences in the diurnal amplitude and phase of the UTH with respect to the microwave observations over both land and oceanic regions. Over land, the GA-3 model shows larger diurnal amplitude than the microwave observations, whereas the CAM-5 model shows lower amplitude. Over the oceanic regions, GA-3 shows smaller amplitudes than the microwave observations, whereas the CAM- 5 model amplitudes are comparable to the observations. The diurnal maximum and minimum are also in disagreement with the observations. The differences are larger over land with a maximum difference of $6 \mathrm{~h}$ in diurnal maximum in GA-3 and a maximum difference of around $5 \mathrm{~h}$ in diurnal minimum in CAM- 5 .

The comparisons between the models and microwave observations over land show that the CAM-5 model is in better agreement with the microwave observation in terms of the diurnal amplitude and the diurnal maximum than the GA-3 model. Over ocean, the diurnal maximum in the GA-3 model is in close agreement with the observations but the diurnal amplitude in CAM-5 model shows a better agreement with the observations as compared to the GA-3 model.

Another important aspect that we investigate in the paper is the cause of the difference in the diurnal cycles of IR and microwave observations. We have demonstrated that the cloud-driven differential sampling between IR and microwave can indeed shift the phase by 0.1 to $1.65 \mathrm{~h}$ in the IR diurnal cycle. In addition, based on CAM model simulations, we have shown that the cloud fraction criterion for IR samplings to be used in the CAM model can range between 0.52 to nearly one, depending upon the regions in consideration. A cloud fraction threshold lying within the range of 0.3-0.4, typically used in model-IR data comparisons might introduce significant phase lag in the UTH diurnal cycle.

This study highlights the limitations of models in simulating a correct diurnal cycle of UTH. The comparison with observations could also assist in developing parameterization schemes which will regulate the evolution of humidity in models until full resolution of convection becomes the norm.

Acknowledgments: We thank David Parker for his valuable comments. We thank Andrew Gettelman for CAM-5 model data and Prince Xavier for helping in GA-3 model run. VOJ was supported by the U.K. Department of Energy and Climate Change (DECC) and Department of Environment, Food and Rural Affairs (DEFRA) Integrated Climate Programme (GA01101) and the EUMETSAT CMSAF. A.K. and S.A.B. were supported by the Swedish Science Council and the Swedish Space Board. Thanks to Lisa Neclos, NOAA CLASS for AMSU-B and MHS Level-1b data and EUMETSAT NWP-SAF for the software to process the data. We acknowledge the Institut Pierre-Simon Laplace's climate data service for facilitating the access of METEOSAT data.

Author Contributions: This work was carried out while Ajil Kottayil was with the Dept. of Space Science, Lulea University of Technology, Sweden. He was involved in preparing the data, data analysis and manuscript writing. Viju O. John was also involved in data preparation and has done editing on the manuscript. Stefan Buehler was involved in the initial conceptualization of the work and has critically supervised the work and the manuscript writing. K Mohanakumar has provided scientific comments on the work.

Conflicts of Interest: The authors declare no conflict of interest. 


\section{References}

1. Yang, G.Y.; Slingo, J. The diurnal cycle in the tropics. Mon. Weather Rev. 2000, 129, 784-801.

2. Soden, B.J. The diurnal cycle of convection, clouds, and water vapor in the tropical upper troposphere. Geophys. Res. Lett. 2000, 27, 2173-2176.

3. Soden, B.J. The impact of tropical convection and cirrus an upper tropospheric humidity: A lagrangian analysis of satellite measurements. Geophys. Res. Lett. 2004, 31, doi:10.1029/2004GL020980.

4. Seidel, D.J.; Free, M.; Wang, J. Diurnal cycle of upper-air temperature estimated from radiosondes. J. Geophys. Res. (Atmos.) 2005, 110, D09102, doi:10.1029/2004JD005526.

5. Miloshevich, L.M.; Vömel, H.; Whiteman, D.N.; Leblanc, T. Accuracy assessment and correction of vaisala RS92 radiosonde water vapor measurements. J. Geophys. Res. 2009, 114, D11305, doi:10.1029/2008JD011565.

6. Kottayil, A.; Buehler, S.A.; John, V.O.; Miloshevich, L.M.; Milz, M.; Holl, G. On the importance of Vaisala RS92 radiosonde humidity corrections for a better agreement between measured and modeled satellite radiances. J. Atmos. Oceanic Technol. 2012, 29, 248-259, doi:10.1175/JTECH-D-11-00080.1.

7. Soden, B.J.; Bretherton, F.P. Interpretation of TOVS water vapor radiances in terms of layer-average relative humidities: Method and climatology for the upper, middle, and lower troposphere. J. Geophys. Res. 1996, 101, 9333-9343, doi:10.1029/96JD00280.

8. Buehler, S.A.; Kuvatov, M.; John, V.O.; Milz, M.; Soden, B.J.; Jackson, D.L.; Notholt, J. An upper tropospheric humidity data set from operational satellite microwave data. J. Geophys. Res. 2008, 113, D14110, doi:10.1029/ 2007JD009314.

9. John, V.O.; Soden, B.J. Temperature and humidity biases in global climate models and their impact on climate feedbacks. Geophys. Res. Lett. 2007, 34, L18704, doi:10.1029/2007GL030429.

10. Iacono, M.J.; Delamere, J.S.; Mlawer, E.J.; Clough, S.A. Evaluation of upper tropospheric water vapor in the NCAR Community Climate Model (CCM3) using modeled and observed HIRS radiances. J. Geophys. Res.: Atmos. 2003, 108, 4037, doi:10.1029/2002JD002539.

11. Allan, R.P.; Ringer, M.A.; Slingo, A. Evaluation of moisture in the Hadley Centre climate model using simulations of HIRS water-vapor channel radiances. Q. J. R. Meteorol. Soc. 2003, 129, 3371-3389, doi:10.1256/ qj.02.217.

12. Gettelman, A.; Collins, W.D.; Fetzer, E.J.; Eldering, A.; Irion, F.W.; Duffy, P.B.; Bala, G. Climatology of upper-tropospheric relative humidity from the atmospheric infrared sounder and implications for climate. J. Clim. 2006, 19, 6104-6121, doi:10.1175/JCLI3956.1.

13. Spangenberg, D.A.; Mace, G.G.; Ackerman, T.P.; Seaman, N.L.; Soden, B.J. Evaluation of model-simulated upper troposphere humidity using $6.7 \mu \mathrm{m}$ satellite observations. J. Geophys. Res. 1997, 102, 25737-25749.

14. Tian, B.; Fetzer, E.J.; Kahn, B.H.; Teixeira, J.; Manning, E.; Hearty, T. Evaluating CMIP5 models using AIRS tropospheric air temperature and specific humidity climatology. J. Geophys. Res.: Atmos. 2013, 118, 114-134, doi:10.1029/2012JD018607.

15. Jiang, J.H.; Su, H.; Zhai, C.; Perun, V.; del Genio, A.D.; Nazarenko, L.S.; Donner, L.J.; Horowitz, L.W.; Seman, C.J.; Cole, J.Evaluation of cloud and water vapor simulations in CMIP5 climate models using NASA A-Train satellite observations. J. Geophys. Res.: Atmos. 2012, 117, D14105, doi:10.1029/2011JD017237.

16. Slingo, A.; Hodges, K.I.; Robinson, G.J. Simulation of the diurnal cycle in a climate model and its evaluation using data from Meteosat 7. Q. J. R. Meteorol. Soc. 2004, 130, 1449-1467, doi:10.1256/qj.03.165.

17. MacKenzie, I.A.; Tett, S.F.B. Lindfors, A.V. Climate model-simulated diurnal cycles in HIRS clear-sky brightness temperatures, J. Clim. 2012, 25, 5845-5863, doi:10.1175/JCLI-D-11-00552.1.

18. Zhang, Y.; Klein, S.A.; Liu, C.; Tian, B.; Marchand, R.T.; Haynes, J.M.; McCoy, R.B.; Zhang, Y.; Ackerman, T.P. On the diurnal cycle of deep convection, high-level cloud, and upper troposphere water vapor in the Multiscale Modeling Framework. J. Geophys. Res. 2008, 113, D16105, doi:10.1029/2008JD009905.

19. Eriksson, P.; Rydberg, B.; Johnston, M.; Murtagh, D.P.; Struthers, H.; Ferrachat, S.; Lohmann, U. Diurnal variations of humidity and ice water content in the tropical upper troposphere. Atmos. Chem. Phys. 2010, 10, 11519-11533, doi:10.5194/acp-10-11519-2010.

20. Chung, E.-S.; Soden, B.J.; Sohn, B.J.; Schmetz, J. An assessment of the diurnal variation of upper tropospheric humidity in reanalysis data sets. J. Geophys. Res.: Atmos. 2013, 118, 3425-3430, doi:10.1002/jgrd.50345. 
21. Eriksson, P.; Rydberg, B.; Sagawa, H.; Johnston, M.S.; Kasai, Y. Overview and sample applications of SMILES and Odin-SMR retrievals of upper tropospheric humidity and cloud ice mass. Atmos. Chem. Phys. 2014, 14, 12613-12629, doi:10.5194/acp-14-12613-2014.

22. Saunders, R.W.; Hewison, T.J.; Stringer, S.J.; Atkinson, N.C. The radiometric characterization of AMSU-B. IEEE Trans. Microw. Theory 1995, 43, 760-771.

23. Bonsignori, R. The Microwave Humidity Sounder (MHS): In-orbit performance assessment. Proc. SPIE 2007, doi:10.1117/12.737986.

24. John, V.O.; Holl, G.; Atkinson, N.; Buehler, S.A. Monitoring scan asymmetry of microwave humidity sounding channels using simultaneous all angle collocations (SAACs). J. Geophys. Res. 2013, doi:10.1002/ jgrd.50154.

25. Brogniez, H.; Roca, R.; Picon, L. A clear-sky radiance archive from Meteosat "water vapor" observations. J. Geophys. Res. 2006, 111, D21109, doi:10.1029/2006JD007238.

26. Gettelman, A.; Morrison, H.; Ghan, S.J. A new two-moment bulk stratiform cloud microphysics scheme in the Community Atmosphere Model, version 3 (CAM3). Part II: Single-column and global results. J. Clim. 2008, 21, 3660, doi:10.1175/2008JCLI2116.1.

27. Gettelman, A.; Liu, X.; Ghan, S.J.; Morrison, H.; Park, S.; Conley, A.J.; Klein, S.A.; Boyle, J.; Mitchell, D.L.; Li, J.-L.F. Global simulations of ice nucleation and ice supersaturation with an improved cloud scheme in the community atmosphere model. J. Geophys. Res. 2010, 115, doi:10.1029/2009jd013797.

28. Neale, R.B.; Richter, J.H.; Conley, A.J.; Park, S.; Lauritzen, P.H.; Gettelman, A.; Williamson, D.L.; Rasch, P.J.; Vavrus, S.J.; Taylor, M.A.; et al. Description of the NCAR Community Atmosphere Model (CAM 5.0); NCAR Technical Note; NCAR: Boulder, CO, USA, 2010.

29. Walters, D.N.; Best, M.J.; Bushell, A.C.; Copsey, D.; Edwards, J.M.; Falloon, P.D.; Harris, C.M.; Lock, A.P.; Manners, J.C.; Morcrette, C.J.; et al. The met office unified model global atmosphere 3.0/3.1 and jules global land 3.0/3.1 configurations. Geosci. Model Dev. 2011, 4, 919-941, doi:10.5194/gmd-4-919-2011.

30. Taylor, K.E.; Stouffer, R.J.; Meehl, G.A. An Overview of CMIP5 and the Experiment Design. Bull. Am. Meteorol. Soc. 2012, 93, 485-498, doi:10.1175/BAMS-D-11-00094.1.

31. Kottayil, A.; John, V.O.; Buehler, S.A. Correcting diurnal cycle aliasing in satellite microwave humidity sounder measurements. J. Geophys. Res. 2013, 118, 101-113, doi:10.1029/2012JD018545.

32. Buehler, S.A.; Kuvatov, M.; Sreerekha, T.R.; John, V.O.; Rydberg, B.; Eriksson, P.; Notholt, J. A cloud filtering method for microwave upper tropospheric humidity measurements. Atmos. Chem. Phys. 2007, 7, 5531-5542, doi:10.5194/acp-7-5531-2007.

33. Buehler, S.A.; John, V.O. A simple method to relate microwave radiances to upper tropospheric humidity. J. Geophys. Res. 2005, 110, D02110, doi:10.1029/2004JD005111.

34. John, V.O.; Buehler, S.A.; Courcoux, N. A cautionary note on the use of gaussian statistics in satellite based UTH climatologies. IEEE Geosci. Remote Sens. Lett. 2006, 3, 130-134, doi:10.1109/LGRS.2005.859350.

35. Lindfors, A.V.; MacKenzie, I.A.; Tett, S.F.B.; Shi, L. Climatological diurnal cycles in clear-sky brightness temperatures from the High-Resolution Infrared Radiation Sounder (HIRS). J. Atmos. Ocean. Technol. 2011, 28, 1199-1205, doi:10.1175/JTECH-D-11-00093.1.

36. John, V.O.; Allan, R.P.; Bell, B.; Buehler, S.A.; Kottayil, A. Assessment of inter-calibration methods for satellite microwave humidity sounders. J. Geophys. Res. 2013, 118, 1-13, doi:10.1002/jgrd.50358.

37. John, V.O.; Holl, G.; Allan, R.P.; Buehler, S.A.; Parker, D.E.; Soden, B.J. Clear-sky biases in satellite infra-red estimates of upper tropospheric humidity and its trends. J. Geophys. Res. 2011, 116, D14108, doi:10.1029/ 2010JD015355.

38. Holl, G.; Buehler, S.A.; Rydberg, B.; Jiménez, C. Collocating satellite-based radar and radiometer measurements-Methodology and usage examples. Atmos. Meas. Tech. 2010, 3, 693-708, doi:10.5194/ amt-3-693-2010.

39. Roca, R.; Brogniez, H.; Picon, L.; Desbois, M. High resolution observations of free tropopsheric humidity from METEOSAT over the indian ocean. In Proceedings of the 2nd MEGHA-TROPIQUES Scientific Workshop, Paris, France, 2-6 July 2001.

40. Bodas-Salcedo, A.; Webb, M.J.; Bony, S.; Chepfer, H.; Dufresne, J.-L.; Klein, S.A.; Zhang, Y.; Marchand, R.; Haynes, J.M.; Pincus, R.; et al. COSP: Satellite simulation software for model assessment. Bull. Amer. Met. Soc. 2011, 92, 1023-1043, doi:10.1175/2011BAMS2856.1. 
41. Sohn, B.J.; Schmetz, J.; Tjemkes, S.; Koenig, M.; Lutz, H.; Arriaga, A.; Chung, E.S. Intercalibration of the Meteosat-7 water vapor channel with SSM/T-2. J. Geophys. Res.: Atmos. 2000, 105, 15673-15680, doi:10.1029/2000JD900188.

42. Chung, E.S.; Sohn, B.J.; Schmetz, J.; Koenig, M. Diurnal variation of upper tropospheric humidity and its relations to convective activities over tropical africa. Atmos. Chem. Phys. 2007, 7, 2489-2502, doi:10.5194/ acp-7-2489-2007.

43. Tan, J.; Jakob, C. A three-hourly data set of the state of tropical convection based on cloud regimes. Geophys. Res. Lett. 2013, 40, 1415-1419, doi:10.1002/grl.50294.

44. Millan, L.; Read, W.; Kasai, Y.; Lambert, A.; Livesey, N.J.; Mendrok, A.; Sagawa, H.; Sano, T.; Shiotani, D.L.; Wu, M. SMILES ice cloud products. J. Geophys. Res.: Atmos. 2013, 118, doi:10.1002/jgrd.50322.

45. Jiang, J.H.; Su, H.; Zhai, C.; Shen, T.J.; Wu, T.; Zhang, J.; Cole, J.N.S.; von Salzen, K.; Donner, L.J.; Seman, C.; et al. Evaluating the diurnal cycle of Upper-tropospheric ice clouds in climate models using SMILES observations. J. Atmos. Sci. 2015, 72, 1022-1044, doi:10.1175/JAS-D-14-0124.1.

46. Pierrehumbert, R.T.; Roca, R. Evidence for control of Atlantic subtropical humidity by large scale advection. Geophys. Res. Lett. 1998, 25, 4537-4540, doi:10.1029/1998GL900203.

47. Kottayil, A.; Satheesan, K. Enhancement in the upper tropospheric humidity associated with aerosol loading over tropical pacific. Atmos. Environ. 2015, 122, 148-153, doi:10.1016/j.atmosenv.2015.09.043.

48. Hoareau, C.; Keckhut, P.; Baray, J.-L.; Robert, L.; Courcoux, Y.; Porteneuve, J.; Vömel, H.; Morel, B. A Raman lidar at La Reunion $\left(20.8^{\circ} \mathrm{S}, 55.5^{\circ} \mathrm{E}\right)$ for monitoring water vapor and cirrus distributions in the subtropical upper troposphere: Preliminary analyses and description of a future system. Atmos. Meas. Tech. 2012, 5, 1333-1348, doi:10.5194/amt-5-1333-2012.

49. Hoareau, C.; Keckhut, P.; Noel, V.; Chepfer, H.; Baray, J.-L. A decadal cirrus clouds climatology from ground-based and spaceborne lidars above the south of France $\left(43.9^{\circ} \mathrm{N}-5.7^{\circ} \mathrm{E}\right)$. Atmos. Chem. Phys. 2013, 13, 6951-6963, doi:10.5194/acp-13-6951-2013.

(c) 2016 by the authors; licensee MDPI, Basel, Switzerland. This article is an open access article distributed under the terms and conditions of the Creative Commons by Attribution (CC-BY) license (http://creativecommons.org/licenses/by/4.0/). 